\title{
TERRITÓRIO E POPULAÇÃO: ENTRE A GOVERNAMENTÁLIDADE E A RESISTÊNCIA
}

\section{Junia Ferrari ${ }^{1}$}

\begin{abstract}
Resumo: A governamentalidade, segundo Foucault, é uma razão de Estado que têm a população como objeto, a economia política como principal saber e os dispositivos como instrumentos estratégicos de poder para garantir o controle dessa população no sentido de produzir a melhor economia. Se entendemos dispositivo como um conjunto de elementos discursivos e não discursivos que cumprem funções estratégicas para uma determinada governamentalidade, é possível ver muitas aproximações com o urbanismo, aqui compreendido como um conjunto de saberes discursivos e não discursivos que determina ações de controle e ordenamento da população no território - onde se trabalha, reside, circula, consome etc., a fim de garantir a melhor economia. Por outro lado, essa mesma cidade urbanisticamente determinada também abriga territórios com populações comprometidas corporalmente em potentes ações de resistência, ou seja, em lutas que estão para além de meras reações à governamentalidade, e que expressam o poder em seu caráter operatório e positivo. Partindo dessas premissas, o que se pretende discutir neste ensaio, tendo como referencia algumas práticas urbanísticas no território, são esses diferentes mecanismos de atuação do poder seja como força disciplinadora e normalizadora biopolítica em busca de garantir a governamentalidade, seja a partir de potentes linhas de força no sentido da recusa em ser governado ou conduzido.
\end{abstract}

Palavras-chave: Governamentalidade. Poder. Dispositivo. Urbanismo. Resistência.

\section{INTRODUÇÃO²}

A questão do poder perpassa grande parte da obra de Foucault e foi fundamental para a leitura que o filósofo fez da contemporaneidade. Entretanto, segundo o autor, o objetivo de seu trabalho não foi analisar o fenômeno do poder, mas elaborar o que ele chamou de uma "história dos diferentes modos pelos quais os seres humanos se tornaram sujeitos” (FOUCAULT, 2013a, p.273). Dito

1 Doutora em Arquitetura e Urbanismo e Professora do Departamento de Urbanismo da Escola de Arquitetura da Universidade Federal de Minas Gerais (EA-UFMG) - E-mail: juniaferrari15@gmail.com

$2 \mathrm{O}$ tema deste ensaio é um desdobramento de pesquisa desenvolvida por ocasião do doutorado e, nessa medida, resgata várias formulações desse trabalho. 
de outra maneira, interessava-lhe os processos de objetivação e subjetivação que transformam o homem em sujeito - seja pela linguagem, sexualidade, economia, conhecimento, dentre outros. Na primeira hora da aula de 5 de janeiro de 1983, em seu curso do Collège de France e já próximo do final de sua vida, o filósofo fez uma retrospectiva de seu trabalho e reavaliou o conjunto de sua obra sintetizando-o na seguinte periodização: primeiro em torno da investigação sobre a veridicção; no segundo momento, em torno da compreensão do que ele nomeou por governamentalidade; e no terceiro e ultimo período se ocupou, ainda que de forma inacabada, em discutir as formas de subjetivação do sujeito (FOUCAULT, 2010a).

À procura do que chamou por veridicção, ele se dedicou ao estudo do conhecimento e dos saberes, não em busca daquilo que fosse verdadeiro, mas das regras e normas segundo as quais se estabelecia o verdadeiro ou o falso a respeito de um determinado tema ou objeto (REVEL, 2005). Em outros termos, foi o período no qual o filósofo investigou as condições de possibilidade para o saber em determinados momentos históricos - ou a episteme (como ele denominou) daquele tempo. Para Foucault, essas mudanças nos estatutos da veridicção e, consequentemente, no entendimento do que é ou não considerado um saber em uma determinada época são estabelecidas aprioristicamente. Isto significa que uma série de fatores - políticos, sociais, econômicos etc.- vão se constituindo gradativamente ao longo do tempo, criando as condições específicas para o 'saber verdadeiro' de um determinado momento histórico. Por exemplo, houve uma época em que as condições de veridicção, ou episteme, apontavam para a crença e, consequentemente para um saber, que se constituía em torno do geocentrismo, ou seja, de acreditar que a terra mantinha uma posição central em relação aos demais astros do universo. Em outro momento, por sua vez, em função de mudanças nos procedimentos de observação, das inúmeras rotas mercantilistas experimentadas em todo o planeta, bem como de outros interesses religiosos e sociais, abandona-se o modelo geocêntrico, e isso deixa de se constituir como uma verdade.

Nessa busca em torno de compreender como a episteme e os saberes se transformam em determinados momentos, Foucault inaugura uma nova etapa de seu trabalho voltando seu interesse para essas tais condições externas que definem a veridicção de uma época. Para o autor, trata-se de um conjunto de elementos de natureza essencialmente estratégica, constituído para atender interesses específicos de uma determinada razão de Estado, e que tem nos saberes importantes "peças de relações de poder" (FOUCAULT, 2008a, p.11-12). Neste 
segundo momento de sua trajetória, Foucault introduz essas relações de poder como instrumentos de análise capaz de explicar a produção dos saberes. É uma importante inflexão em relação ao momento anterior: do questionamento de 'como' os saberes se transformam e estabelecem regularidades para 'por que' (ou a partir de quais mecanismos) eles se constituem (MACHADO, 2015). Embora o objetivo de suas análises ainda continue sendo a constituição dos saberes, interessava-lhe, principalmente, a investigação dos poderes que lhe são intrinsecamente associados (MACHADO, 2015).

A partir daí, o autor se volta para as técnicas e estratégias de poder utilizadas para direcionar o saber e, de modo consequente, para o entendimento de como o comportamento ou conduta dos outros se deixa orientar naquela direção. Em outros termos, como nos deixamos governar ou ser conduzidos. Para tanto, Foucault toma como recorte empírico o poder que se exerce a partir das instituições governamentais - hospícios, centros de detenção, hospitais, escolas etc. -, e que expressam as condutas sociais desejadas por uma forma específica de governo ${ }^{3}$ dos outros, a qual ele nomeia por governamentalidade ${ }^{4}$. O deslocamento de suas investigações consistiu em "passar da análise da norma à dos exercícios do poder; e passar da análise dos exercícios do poder aos procedimentos, digamos, de governamentalidade, [a partir] do exemplo da criminalidade e das disciplinas" (FOUCAULT, 2010a, p.6). Em síntese, o autor se volta para a compreensão de como se dão as relações de poder nas práticas e procedimentos de governo, a fim de desvelar por que (ou a partir de quais mecanismos) os saberes se constituem como elementos estratégicos, parte fundamental de um dispositivo que atua no sentido de viabilizar uma determinada razão de Estado.

Para Foucault, essa governamentalidade é essencialmente urbana, assim como a polícia e suas atribuições de normalizar a população e o território (FOUCAULT, 2008b). É aí, no espaço urbano, que se estabelece o estreito vínculo entre razão de Estado, poder de polícia e atividades de mercado no sentido de promover o 'bom governo' e o 'melhor viver' da população. É nessa condição do território que a cidade-mercado-indústria encontra o campo fértil para sua realização. Ou seja, a ordenação e o disciplinamento do território desempenharam algumas das condições de possibilidade para que uma determinada razão

\footnotetext{
3 Segundo Foucault o poder de polícia é distinto do poder de justiça. A polícia, nos séculos XVII e XVIII, era essencialmente pensada no sentido de promover a urbanização do território, regulamentando os lugares onde a população se reunia, morava e circulava (FOUCAULT, 2008b).

4 As técnicas de disciplina e vigilância (com base no panóptico de Bentham) utilizadas nas prisões, o levaram a estabelecer uma relação de aproximação com as técnicas utilizadas nos estabelecimentos escolares e militares, e concluir que eram, de fato, parte de um mecanismo maior de uma determinada forma de governar.
} 
de Estado pudesse se estabelecer e se consolidar na Europa naquele momento, e não o contrário.

Por outro lado, outras práticas relativas também às artes urbanas se constituíram em vários lugares do mundo na forma de lutas e de resistência contra essa mesma racionalidade, e anunciando outras formas de uso e ocupação/apropriação do território. Ou seja, se o espaço urbano se mostrou um meio fértil para aplicação de práticas controladoras, por outro lado significa também potência que viabiliza formas de resistências nas disputas pela cidade. Se tem servido como suporte para as estratégias do Urbanismo, também tem se configurado como arena para ações em outras direções, a saber, de resistência contra o governo dos outros.

Há, portanto, uma centralidade dos sujeitos e do território ${ }^{5}$ na obra de Foucault. Nesse sentido, o que se pretende discutir neste ensaio, tendo como referencia algumas práticas urbanísticas que determinam as interdições e ações dos sujeitos no território, são alguns desses mecanismos que atuam ora como forças disciplinadoras e normalizadoras biopolíticas em busca de garantir a governamentalidade, ora a partir de potentes linhas de força no sentido da recusa em ser governado ou conduzido. Enfim, a proposta é trilhar um caminho que se sustenta num duplo questionamento: das práticas urbanas como dispositivo a serviço da governamentalidade e como oportunidades para a atuação do poder na forma de resistências.

Para tanto, este trabalho se estrutura em três partes, além desta introdução e das considerações finais: a primeira se constitui pela contextualização de alguns elementos conceituais estruturantes da obra de Foucault, como a discussão em torno do entendimento das relações de poder, exatamente porque acompanha todo o trabalho dando-lhe sustentação. A segunda parte consiste em, partir de algumas práticas urbanísticas, interrogar essa ciência e suas interfaces com a governamentalidade. Mais especificamente, como as estratégias da Disciplina e do Biopoder podem ser percebidas no território citadino. A terceira parte, por sua vez, traz algumas formas de resistências urbanas, cujas bases de sustentação também incluem o território como referência.

É importante registrar que não há aqui qualquer pretensão em esgotar tão extenso conteúdo, nem de se chegar a respostas ou "soluções de cidade", apenas a possibilidade de expor outros modos possíveis de interrogá-la. Mais o percurso

5 Adotamos aqui o termo 'território', tal como em Foucault, ou seja, com os dois sentidos que ele lhe atribui: um sentido geográfico e outro jurídico-político, que significa "aquilo que é controlado por um tipo de poder" (FOUCAULT, 2015a, p.250). 
do que as conclusões, entendendo que a busca por um produto final acabado e fechado é incongruente com as indefinidas possibilidades de transformação da cidade.

\section{PODER E GOVERNAMENTALIDADE}

Foucault não se limitou à "inter-relação conceitual de saberes", mas buscou articulá-los com alguns elementos não discursivos, sejam as instituições (hospital, família, escola), sejam as transformações político-sociais (sobretudo a Revolução Francesa). A necessidade de entender os mecanismos e estratégias dessas articulações conduziram-no às relações de poder, buscando as condições externas aos próprios saberes que os situavam enquanto elementos de natureza essencialmente estratégica (MACHADO, 2015).

Entretanto, a análise das relações de poder o levou a um impasse a partir da segunda metade dos anos 1970, a saber, à necessidade de romper com as duas visões de poder até então dominantes e com as quais ele não via perspectiva de uma grade possível de trabalho. Uma à qual ele atribuiu o nome de "visão economicista" (abordagem de origem jurídica), a partir da qual se justifica o poder pela forma contratualista, ou seja, pelo modelo hobbesiano ${ }^{6}$ que se impôs ao longo dos séculos XVI e XVII. A segunda visão, por sua vez, parte de uma concepção que privilegia o conteúdo belicoso ou repressivo do poder (POGREBINSCHI, 2004), seja pela associação entre poder e repressão (hipótese de Reich), ou entre poder e guerra (hipótese de Nietzsche) ${ }^{7}$.

[...] dois esquemas de análise do poder: o esquema contrato-opressão, que é, se vocês preferirem, o esquema jurídico, e o esquema guerra-repressão, ou dominação-repressão, no qual a oposição pertinente não é a do legitimo e do ilegítimo, como no esquema precedente, mas a oposição entre luta e submissão. (FOUCAULT, 2010b, p.17).

Ambos os entendimentos eram limitantes à noção de poder para Foucault, pois o qualificavam de modo descendente e centralizado, no primeiro caso, ou repressivo e autoritário, no segundo modelo. De acordo com o autor, era neces-

6 Para Hobbes, a cooperação entre os homens só é possível pela via artificial, ou seja, a partir da transferência mútua de direito estabelecida por meio de um contrato. Como Hobbes é um absolutista convicto, para ele essa transferência deve se dar ao soberano, o Leviatã encarregado de promover a paz e que não precisa dar satisfações a qualquer pessoa, pois só presta contas diretamente a Deus sob pena de morte eterna (HOBBES, 1999).

7 Na visão economicista, que Foucault nomeia por 'hipótese de Reich', ele se baseia nas abordagens propostas por Hegel, Freud e Reich, a partir das quais o poder está associado somente à ideia de repressão. A segunda visão também confere ao poder um atributo de dominação pela força, ou seja, não há saída possível fora da guerra, abordagem que ele nomeia por 'hipótese de Nietzsche'. (FOUCAULT, 2010b). 
sário descentralizar o poder, retirando-o das mãos do Estado para analisá-lo em seus mecanismos moleculares e infinitesimais, numa trajetória em sentido contrário, ou seja, das pontas para o centro, uma análise ascendente: “[...] se o poder consiste em relações de força, múltiplas e móveis, desiguais e instáveis, é evidente que ele não pode emanar de um ponto central, mas sim de instâncias periféricas e localizadas" (POGREBINSCHI, 2004, p.188).

Este deslocamento, que destitui o poder da condição de monopólio do Estado e o analisa a partir de suas formas mais locais, como capilaridades, tem como pressuposto o necessário abandono dos dois modelos: da visão jurídico-legal (contratualista) moderna, pois o poder deixa de ser entendido como um atributo de direito ou objeto que se aliena ou negocia; e da concepção de guerra ou repressão, pois o caráter autoritário e dual desse modelo não comporta toda a multiplicidade que Foucault atribui ao poder. Para ele, era preciso compreende-lo como uma ação dinâmica e "operatória", parte constitutiva de todos os tipos de relação (família, academia, governo, sexo). Era necessário, portanto, um duplo corte: do sentido da materialidade do poder e, principalmente, de seu vínculo com a soberania que já foi deposta. Para ele, "No pensamento e na análise política ainda não cortaram a cabeça do rei” (FOUCAULT,1977, p.86).

A ruptura com a linguagem da guerra e com a visão jurídico-legal ou contratualista marcou uma inflexão importante em seu percurso pois, a partir daí, o autor passa a discutir como se dão as relações de poder como "práticas de governo", a fim de desvelar por que (ou a partir de quais mecanismos) os saberes se constituem como elementos de um dispositivo essencialmente estratégico, parte fundamental das relações de poder. Para ele, essas práticas representam uma modalidade específica dentre as demais formas de conduta e governo dos homens, que diz respeito exclusivamente ao exercício da soberania política e à qual ele nomeia por governamentalidade.

\subsection{A GOVERNAMENTALIDADE}

A partir do século XVI, a Europa enfrenta o desafio da convergência de dois processos importantes: um que diz respeito à superação de uma sociedade basicamente feudal e dispersa em direção a uma concentração territorial do Estado nação, o que passa a demandar novos procedimentos no que diz respeito à administração e à gestão mais centralizadas; e outro, que se traduz pelo movimento de Reforma da Igreja - posteriormente pela Contrarreforma -, que por sua vez modificam e diversificam os modos como a sociedade passa a ser conduzida espiri- 
tualmente. Em suma, ao mesmo tempo em que há um movimento de dispersão pela religião há, em contraposição, um movimento de concentração do território por parte do Estado nação.

A essa organização de Estado nascente cabe uma função bem mais ampliada do que aquela atribuída anteriormente ao príncipe. Não mais os súditos dóceis, "sujeitos de direito sobre os quais se exerce a soberania política", mas "uma população que um governo deve administrar" (FOUCAULT, 2008c, p.30). A população passa a ser vista como questão de ordem política, "como problema a um só tempo científico e político, como problema biológico e como problema de poder" (FOUCAULT, 2010b, p.206).

Nessa perspectiva, se anunciam outros interesses - população, reprodução, acumulação, concorrência -, inaugurando um momento singular de governo dos outros, para o qual é necessário se constituir uma racionalidade própria, ou melhor, uma razão de Estado específica ${ }^{8}$.

A noção de economia também se modifica. Da ideia inicial de governo da família (seus bens, as associações necessárias etc.), ela se amplia para uma rede maior que inclui a população, a riqueza e o território, numa escala que extrapola a gestão doméstica e constitui uma ciência denominada 'economia política'.

Há, portanto, um deslocamento do indivíduo para a população, e também uma alteração no conceito de família. Esta passa, de modelo de boa economia (da adequada administração dos bens a partir de um escala doméstica), para uma condição de instrumento de controle dessa população, a partir de campanhas dedicadas ao estímulo do casamento como forma de proteção à propriedade privada e de impulso à natalidade, além da garantia de um padrão de população menos sujeito às miscigenações indesejadas.

Essa razão de Estado que começa a se constituir a partir do século XVIII terá seu objeto privilegiado no par população-riqueza. Seus mecanismos de atuação serão, a princípio, as tecnologias político-militares (disciplina) e uma polícia urbana (vigilância). Segundo Revel (2005, p.55), "no cruzamento dessas duas tec-

\footnotetext{
8 Segundo Foucault, razão de Estado e governamentalidade não são a mesma coisa. A primeira se relaciona com o conjunto de estratégias de poder/saber específicos de um determinado momento histórico de governo (de Estado). O conceito de governamentalidade, por sua vez, não está associado exclusivamente a algumas práticas governamentais constitutivas de um regime de poder específico, mas a uma forma mais ampliada e abstrata que compreende as diversas maneiras "como se conduz a conduta dos homens". O termo governamentalidade se associa ao campo estratégico das relações de poder no seio do qual se estabelecem todos os tipos de conduta, que podem se dar no âmbito do governo (Estado), mas também em outros tipos de relação (de trabalho, educacional, familiar, de si mesmo, dentre outras): "Assim, razão de Estado e governamentalidade não são a mesma coisa, embora esta reúna as estratégias de exercício do poder da razão de Estado". (TEMPLE, 2011, p.122).
} 
nologias encontra-se o comércio e a circulação interestatal da moeda", ou seja, "é do enriquecimento pelo comércio que se espera a possibilidade de aumentar a população, a mão-de-obra, a produção e a exportação" (FOUCAULT, 2008b, p.492). Enfim, "O mercado deve dizer a verdade, deve dizer a verdade em relação à prática governamental” (FOUCAULT, 2008c, p. 44-45). Em outras palavras, delineia-se uma razão de Estado que se esforça permanentemente para uma autolimitação em relação à questão da veridicção estabelecida pelo mercado.

A partir do final do século XVIII e início do século XIX, por sua vez, a população é deslocada para um outro patamar: não mais a soma dos sujeitos de direito, mas "o objeto construído por uma gestão política global da vida dos indivíduos (biopolítica) ${ }^{9 ”}$ " que implica, não apenas a gestão da população, mas "um controle das estratégias que os indivíduos, na sua liberdade, podem ter em relação a eles mesmos e uns em relação aos outros" (REVEL, 2005, p.55).

Nesse sentido será necessário fazer adaptações na população (ajustando-a aos interesses da produção e do consumo nas áreas de interesse do mercado), na legislação (especialmente no que diz respeito ao regime jurídico de terras e da hierarquização dos espaços na cidade), nas técnicas (ferramentas, processos de aprendizagem), no meio ambiente (agua, recursos naturais, clima). O saber (a informação técnica qualificada) passa a ser ainda mais importante e será instrumento estratégico para viabilizar o 'melhor mercado'.

Em síntese, a governamentalidade para Foucault é um conjunto de tecnologias de governo à serviço de uma determinada razão de Estado (mercantilismo, liberalismo ou neoliberalismo), com o objetivo de conduzir a população no sentido da melhor economia:

Por essa palavra, 'governamentalidade', entendo o conjunto constituído pelas instituições, os procedimentos, análises e reflexões, os cálculos e as táticas que permitem exercer essa forma bem específica, embora muita complexa, de poder que tem por alvo principal a população, por principal forma de saber a economia política e por instrumento técnico essencial os dispositivos de segurança. (FOUCAULT, 2008c, p. 145).

Para atingir seus objetivos, a governamentalidade dispõe do dispositivo, instrumento técnico que se constitui de diversos elementos (discursivos e não discursivos), de maneira que os objetivos de uma determinada razão de Estado possam ser alcançados.

9 A noção de biopolítica designa, para Foucault, a maneira pela qual o poder se transforma, entre o final do século XVIII e o começo do século XIX, e passa a governar, não apenas os indivíduos como multiplicidades disciplinando-os para determinados desempenhos, mas a população em todos os aspectos da vida que passaram a ser preocupações políticas - saúde, higiene, alimentação, sexualidade, natalidade (REVEL, 2005). 


\subsection{O DISPOSITIVO URBANISMO}

O urbanismo é definido como a ciência que estuda os fenômenos urbanos, refletindo e planejando as ações sobre a cidade, especialmente após as transformações acarretadas pela revolução industrial ${ }^{10}$. Nessa perspectiva, pode-se afirmar que é o conjunto de conhecimentos técnicos necessários para analisar, discutir e mediar ações específicas de intervenção, controle e ordenamento do território.

O termo dispositivo, segundo a definição de alguns dicionários de língua portuguesa ${ }^{11}$, é um substantivo que significa "mecanismo destinado à obtenção de um fim", e também um adjetivo que nos remete à ideia de "conter uma disposição, ordem ou prescrição". No significado atribuído por Foucault em uma de suas entrevistas, ele o designa como:

[...] um conjunto decididamente heterogêneo que engloba discursos, instituições, organizações arquitetônicas, decisões regulamentares, leis, medidas administrativas, enunciados científicos, proposições filosóficas, morais, filantrópicas. Em suma, o dito e o não dito são os elementos do dispositivo. (FOUCAULT, 2015b, p.364).

É possível reconhecer nesta definição de Foucault, assim como no significado atribuído pelos dicionários populares de língua portuguesa, uma associação do vocábulo a discursos de vários campos de saber (do direito, da ciência, da filosofia, dentre outros), aos quais Foucault nomeia 'ditos' ou elementos discursivos. Da mesma forma, identificam-se também como partes do conceito foucaultiano de dispositivo as instituições e organizações, às quais ele nomeia 'não ditos' ou elementos não discursivos. Portanto, é possível inferir que o termo dispositivo pode ter sido escolhido pelo filósofo exatamente pelo grande alcance de suas interlocuções e significados, dimensão necessária a um conceito de natureza tão abrangente.

Por outro lado, as técnicas de governo que se constituem a partir do século XVII, e que Foucault denomina por governamentalidade, tem nos dispositivos um instrumento essencial para atingir seus fins. Em outras palavras, o dispositivo tem a propriedade de atuar na direção de se obter um propósito e a governamentalidade depende desse tipo de mecanismo para que se viabilizem seus

\footnotetext{
$10 \mathrm{O}$ termo urbanismo deriva dos estudos do engenheiro catalão Ildefonso Cerdá - a Teoria Geral da Urbanização-, publicado em 1867. Entretanto, o termo urbanismo foi identificado por Bardet pela primeira vez no inicio do século XX, em um boletim da Sociedade Geográfica de Neufchatel, França. (CHOAY, 1992). 11 Dicionário Priberam da Língua Portuguesa [em linha], 2008-2013. Disponível em: http://www.priberam. pt/dlpo/dispositivo. Acesso em agosto de 2016.
} 
objetivos - o primeiro é, portanto, condição de realização do segundo.

O dispositivo, por sua vez, se traduz por uma multiplicidade de elementos, alguns do campo do discurso, outros ligados às instituições, à economia, à política etc. (práticas não discursivas), além das linhas de força que impulsionam esses elementos, conferindo-lhe a necessária dinâmica para alcançar seus objetivos. Essas linhas de força, por sua vez, sustentam e são sustentadas por tipos de saber que lhes atribui poder (e vice-e-versa, alimentando a dinâmica). Importante lembrar que não se trata de qualquer saber, mas apenas daqueles reconhecidos como verdades de seu tempo: informação qualificada significa poder.

$\mathrm{O}$ argumento é que o urbanismo tem atuado a partir de práticas discursivas (leis, medidas administrativas, enunciados científicos, proposições filosóficas) e não discursivas (instituições, procedimentos e organizações arquitetônicas), orientadas no sentido do controle e da ordenação dos corpos no território (biopolítica) - onde se trabalha, reside, circula, consome, etc.-, de forma a garantir a manutenção de uma razão de Estado e não de privilegiar o cidadão comum em suas práticas cotidianas.

Cabe-nos aqui avançar no sentido de inquirir algumas dessas práticas a fim de compreender as relações de poder/saber que as atravessam e os objetivos e intenções que as impulsionam, buscando as interfaces que possam caracterizá-las como estratégias a serviço de uma determinada governamentalidade. A composição múltipla de elementos, a função estratégica e o caráter discursivo e prático que possuem tanto o conceito de urbanismo, quanto o de dispositivo, nos levaram a considerar essa possibilidade. Há, por assim dizer, uma cartografia que sinaliza essa aproximação.

\section{A SOCIEDADE NORMALIZADA}

As relações de poder que se configuram no século XVIII se definem como modos de ação que não atuam direta e imediatamente sobre os corpos [como o suplício, no poder soberano, ou como o adestramento na disciplina], mas sobre o meio em que vivem e, consequentemente, sobre suas ações (FOUCAULT, 2013a). Isso significa que o território passa a desempenhar um papel estratégico para a governamentalidade em curso, na medida que representa um meio eficaz para interditar e/ou induzir as ações da população.

É preciso então compreender a natureza do território (meio geográfico e físico) e da população (biologia), de maneira a exercer o poder sobre a articulação 
entre esses elementos (o homem e seu meio), calculando a melhor forma de intervir para garantir a quantidade de população ativa necessária à 'boa economia' (produção, reprodução e consumo) das nações.

Para Foucault a "sociedade da normalização" tem sua origem na associação, ou melhor, na superposição de duas formas distintas (mas complementares) de manifestação do poder: disciplinar e biopoder. O primeiro trabalhando no sentido de reeducar e adestrar os indivíduos, visando sua inserção num quadro de normalidade já estabelecido, e o segundo atuando sobre a população, no sentido de garantir, estatisticamente, a permanência de uma média aceitável da população ativa.

O poder disciplinar e o biopoder, apesar de operarem com mecanismos e estratégias diferentes, tem como denominador comum o uso da norma que, para Foucault, "pode tanto se aplicar a um corpo que se quer disciplinar quanto a uma população [ou cidade] que se quer regulamentar” (FOUCAULT, 2010b, p.213). O que sucede é a prevalência de um determinado modo em um momento específico. Desta forma, é possível identificar-se, em um mesmo período histórico, ações e estratégias sobre o território associadas a ambos os mecanismos, simultaneamente. A norma cumpre um papel decisivo como agente transformador na cidade, pois atua diretamente sobre seu território.

Para isso, a partir do século XVIII, são instituídos dois grandes modelos de organização médica/social cujo rebatimento no território foi fundamental no sentido da reconfiguração do espaço urbano: um modelo suscitado pela lepra e outro pelos surtos de peste.

Para o primeiro caso, a solução era o exílio, a exclusão da cidade. "Medicalizar alguém era mandá-lo para fora e, por conseguinte, purificar os outros" (FOUCAULT, 2015c, p.156). Nesse bojo também são excluídos do convívio da cidade os loucos, os malfeitores e os mortos, os dois primeiros, inclusive, demandando uma arquitetura própria para esse isolamento na forma de manicômios e cadeias.

Para os casos de peste, entretanto, foi adotada uma estratégia diferente, que consistia em isolar as pessoas contaminadas, mas em suas próprias casas, submetendo-as a procedimentos de vigilância, inspeção e controle permanentes. Uma polícia médica que adentrava sistematicamente os domicílios, vasculhando e esquadrinhando os hábitos das pessoas, demarcando espaços e regras de convivência. Essa "medicalização da cidade" resolve um duplo problema: de conter as epidemias que se alastraram na época, além de desempenhar o papel político e social de delimitar o espaço dos diversos grupos na cidade. "A coabitação em um mesmo tecido urbano de pobres e ricos foi considerada um perigo sanitário 
e político para a cidade, o que ocasionou a organização de bairros pobres e ricos, de habitações ricas e pobres" (FOUCAULT, 2015c, p.166).

Assim, a lepra e a peste inauguram duas formas de se exercer o poder sobre aqueles que, de alguma forma, representassem uma perigosa mistura. A lepra marca a exclusão e a separação física de uma parte indesejada da população, e a peste o esquadrinhamento, a hierarquização e a vigilância de outra parte.

A disciplina e o biopoder não atuam no mesmo nível, o que acaba por permitir que atuem conjuntamente, pois um não necessita excluir o outro. Agem de forma articulada e complementar: a disciplina sobre o corpo individual, e o biopoder sobre a população. Na cidade, essa complementaridade se mostrará mais evidente. Desde as intervenções na escala de cada indivíduo ou família, disciplinados em cômodos ou casas identificadas por endereços e tipologias construtivas, até a regulamentação do território, numa escala ampliada que estabelece e gestiona as diversas funções urbanas, inclusive a localização que cabe a cada grupo na cidade.

$\mathrm{Na}$ esteira desse processo de individualização (disciplinar) e de controle da população e da cidade (biopoder e biopolítica), foi desenvolvida uma medicina ou "polícia médica" para garantir a higiene pública e os padrões de cidade condizentes com a burguesia industrial emergente. Essa polícia urbana estava autorizada a intervir sobre a propriedade e a habitação privadas, até então consideradas como lugares sagrados. Assim, o espaço urbano (cidade em geral) e o espaço doméstico no século XIX, especialmente aqueles nos quais circulavam e residiam a burguesia vitoriosa de 1848 (no caso específico da França), foram submetidos a uma série de normalizações e intervenções que modificam definitivamente a estrutura da cidade.

Era a utopia da cidade perfeitamente governada, época dos grandes proje$\operatorname{tos}^{12}$ que buscam a eliminação os vestígios da Idade Média. A meta era criar uma cidade a partir de princípios estético-sanitários que justificassem os necessários procedimentos de exclusão, hierarquização e tratamento de áreas específicas. Em outras palavras, todas as ações e intervenções tinham como objetivo, simultaneamente, atender à necessidade de valorização e qualificação da cidade para um publico específico, e expulsar do convívio citadino a parte indesejada da população.

A arquitetura, que até então esteve mais voltada para as grandes formas em geral: palácios, igrejas, praças, enfim, às necessidades de manifestação do poder,

12 As intervenções do Barão de Haussmann em Paris, no século XIX, influenciaram a maior parte das práticas urbanas na Europa e Américas. No Brasil, foram emblemática as intervenções de Pereira Passos no Rio de Janeiro, bem como o projeto de Aarão Reis para Belo Horizonte. 
da divindade e da força, agora se volta para a habitação particular, até então pouco diferenciada interna e externamente (FOUCAULT, 2015d). Essas regras vão especificar e funcionalizar os espaços de dormir, de comer etc., inclusive no que se refere às habitações operárias da época: "A família operária será fixada; será prescrito para ela um tipo de moralidade, através da determinação de seu espaço de vida" (FOUCAULT, 2015d, p.322). Um disciplinamento ostensivo visando a distribuição espacial dos indivíduos na cidade, assim como o controle do território (meio) de maneira a garantir a segurança e a vitalidade da população dentro dos padrões desejados.

O ordenamento espacial (disciplinar e normalizado) foi, portanto, um procedimento fundamental e estratégico no sentido da implementação dos objetivos da razão de Estado liberal. A partir dele se estabeleceu uma espécie de "classificação dos seres" (taxinomia) - de acordo com a "função" que desempenhassem na cidade -, dispondo-os em bairros ou distritos específicos: "Na disciplina [...] cada um se define pelo lugar que ocupa na série, e pela distância que o separa dos outros." (FOUCAULT, 2014, p.143), tal como nas fábricas. Além disso, era necessário garantir sua permanência em um campo de visibilidade, para isso se estabelecem os endereços: nomes de ruas, bairros, códigos etc. Todas as informações necessárias à localização rápida de cada indivíduo ou família. Ao mesmo tempo, essas intervenções deveriam garantir o movimento regulamentado das riquezas (grandes vias e áreas específicas destinadas à indústria e ao comércio). A circulação passou a desempenhar um papel importante nesse contexto, na medida em que articulava os diferentes espaços, viabilizava o rápido escoamento das mercadorias, além de facilitar o deslocamento das tropas e a vigilância dos corpos.

A determinação minuciosa dos lugares e de seus usos específicos cumpria uma série de funções, tais como manter a vigilância (mediante o endereço, por exemplo), romper as comunicações perigosas (evitando-se os encontros), garantir a manutenção de uma hierarquia (cada grupo deve ocupar uma localização específica na cidade): "Cada indivíduo no seu lugar e em cada lugar um indivíduo” (FOUCAULT, 2014, p.140).

Fica evidente que o urbanismo, a partir de seus elementos constitutivos, atuava de forma estratégica na configuração do território (nas implantações, distribuições, recortes, controles de territórios, organizações de domínios) no sentido de alcançar um objetivo específico. Em outros termos, o dispositivo, até então compreendido a partir de algumas perspectivas - da loucura, do encarceramento, da educação -, demonstrou ter também uma articulação possível com o urbanismo pois, este tem como objeto o território (em todas as suas dimensões), 
tem como sustentação o discurso técnico e como objetivo instrumentalizar a governamentalidade, no sentido de fazer valer a razão de Estado, seja ela liberal ou neoliberal.

\section{OS CONTRAESPAÇOS ${ }^{13}$ OU HETEROTOPIAS COMO RESISTÊNCIÁS}

Assim como a cidade é o espaço do poder é também o espaço da resistência. Se por um lado ela reflete os processos de normalização fundamentados por uma determinada razão de Estado, é certo que também ali o poder se manifesta nas micro escalas locais, a partir de múltiplas ações de resistência, afinal o poder não é monopólio de ninguém mas relação dinâmica que perpassa toda a sociedade. Desta forma, se o território se configura como meio para a disciplina e a normalização biopolíticas, é também capaz de se constituir enquanto espaço de resistência.

Se algumas condutas têm sido impostas aos indivíduos a partir das estruturas de poder na forma de estratégias da razão de Estado (legislação urbanística, por exemplo), por outro lado é possível identificar, também no território, linhas de resistência que se constituem na forma das heterotopias.

A hierarquização dos bairros, a formatação das quadras e das ruas, a circulação privilegiada dos veículos e das mercadorias, enfim, os padrões de normalidade da cidade liberal e neoliberal foram criados a partir da eliminação dos padrões indesejáveis: pobreza, diferença de etnias ${ }^{14}$, morte, doenças, comportamentos pouco familiares (prostíbulos e tabernas, por exemplo) e outras 'mazelas sociais', deslocados para bairros ou áreas fora dos circuitos por onde circulariam as famílias.

Poderíamos associar essa eliminação ou segregação à noção de lugares que se opõem a outros que tendem a apagá-los, e que Foucault nomeia, a princípio, por "contraespaços" ou "utopias situadas, [...] lugares reais fora de todos os lugares" (FOUCAULT, 2013b, p. 20). Como o autor entende o termo utopia como o espaço que verdadeiramente não tem lugar algum (sem topia), ele atribui o nome de heterotopia a esses "espaços absolutamente outros", a essas "utopias situadas", mas que existem enquanto lugares concretos na nossa realidade.

$13 \mathrm{O}$ termo contraespaço foi aqui transcrito da mesma forma que se encontra no texto de Foucault, relativo às Heterotopias, ou seja, metade em itálico (FOUCAULT, 2013b)

14 Para algumas comunidades a diferença de raças é fator de segregação (negros, latinos, índios, etc.) e., para outras, essa separação pode se dar em função das opções religiosas (judeus, mulçumanos etc.). 
Para Foucault, as heterotopias seriam aqueles espaços reais e que foram segregados daqueles disciplinados e normalizados: "esses espaços diferentes, esses outros lugares, essas contestações míticas e reais do espaço em que vivemos" (FOUCAULT, 2013b, p.20-21). Assim, por definição, as heterotopias seriam, a princípio, espaços de contestação ou de resistência em relação àqueles ordenados pelas estruturas de poder, e não apenas ações deliberadas de contraconduta ${ }^{15}$.

Entretanto, apesar dessa noção de contestação atribuída inicialmente à heterotopia, tem havido um entendimento sistemático do termo unicamente associado à ideia de desvio, que por sua vez significa apenas uma das cinco atribuições relativas às heterotopias que Foucault apresenta. Para o autor, os princípios que as caracterizam seriam basicamente: i não há sociedades que não possuam suas heterotopias, pois são ali que se realizam seus desvios; ii todas as heterotopias podem desaparecer em algum momento, assim como outras podem ser criadas; iii as heterotopias têm como regra permitir a justaposição de espaços a princípio incompatíveis; iv frequentemente são associadas a recortes singulares de tempo no sentido de acumular uma determinada cultura, de manter seus registros e histórias; v possuem um sistema de isolamento em relação aos demais espaços que, para ser transposto, demanda certos rituais a partir dos quais os sujeitos são ou não autorizados a penetrá-las. Por fim, Foucault destaca a superposição entre duas ou mais heterotopias, não como princípio, mas como possibilidade.

Assim, as condutas urbanísticas determinam essas zonas apartadas da cidade e, ao mesmo tempo, ajudam a criar espaços intermediários que funcionam como "espelhos". São situações híbridas, nas quais há um desejo de se manter formas mais autônomas de viver e morar (portanto, independentes das normalizações do Estado), ao mesmo tempo que se reproduzem padrões e hábitos de consumo que nos remetem ao repertório das condutas urbanísticas. Há um espaço real onde se vive, mas também um outro distante que se projeta, introjeta e deseja de alguma forma, misturando utopias e heterotopias em um mesmo espaço:

[...] acredito que entre as utopias e estes posicionamentos absolutamente outros, as heterotopias, haveria, sem dúvida, uma espécie de experiência mista, mediana, que seria o espelho. O espelho, afinal, é uma utopia, pois é um lugar sem lugar. No espelho, eu me vejo lá onde não estou, em um espaço irreal que se abre virtualmente atrás da superfície, eu estou lá longe, lá onde não estou, uma espécie de sombra que me dá

15 Poderíamos identificar as heterotopias como contracondutas se fossem ações deliberadas de negação ao ato de ser conduzido. Entretanto, o que se percebe nas descrições dos princípios anunciados por Foucault, mesmo que pouco explorado, é a possiblidade da heterotopia enquanto espaço de resistência não deliberada. Ou seja, não um espaço premeditado de contracondutas (ou contraespaço), mas numa lógica instituinte que constrói algo novo ao mesmo tempo que resiste. 
a mim mesmo minha própria visibilidade, que me permite me olhar lá onde estou ausente: utopia do espelho. Mas é igualmente uma heterotopia, na medida em que o espelho existe realmente, e que tem, no lugar que ocupo, uma espécie de efeito retroativo; é a partir do espelho que me descubro ausente no lugar em que estou porque eu me vejo lá longe (FOUCAULT, 2003, p. 415).

Se a partir da noção de heterotopia Foucault pretendia, a princípio, explicar alguns espaços difíceis de se classificar, seja por estarem segregados do ordenamento tradicional, porque apresentavam formas não reguladas, ou mesmo porque não se constituíam dentro de um determinado repertório tradicional de espaço, hoje em dia esse conceito tem sido utilizado apenas na sua forma negativa, ou seja, como espaços de domínio sujeitos a normas específicas, mas sob o jugo das estruturas de poder (CLAVEL, 2012).

\section{CONSIDERAÇÕES FINAIS}

O território, na era da governamentalidade, adquire status de elemento estruturador: é condição de acesso ao poder e meio para a economia do Estado - no que se refere à produção, à circulação e ao consumo de mercadorias. Desta forma, as propriedades públicas e privadas, bem como todos os discursos a elas associados (normas, procedimentos, leis), passam a ter importância estratégica e precisam ser explicitados, especialmente no que diz respeito à delimitação desse círculo privilegiado.

Há, portanto, uma mudança significativa no que diz respeito ao papel atribuído ao território: não mais a proteção para o soberano, mas o disciplinamento e a normalização que garantam a primazia da propriedade, agora entendida também como mercadoria e referência de poder.

A urbanística, a geografia e a medicina social passam a desempenhar papéis centrais para a viabilização desse projeto de Estado e, nesse sentido, desenvolvem-se uma série de técnicas e procedimentos policiais e médico/sanitaristas que determinam a distribuição dos indivíduos no espaço, organizando-os e aos lugares, de forma funcional e hierárquica. Em relação aos perigos que possam 'contaminar' o tecido urbano, é preciso isolá-los e esquadrinhá-los (modelo de organização baseado na peste) ou segregá-los (modelo da lepra).

O urbanismo estabelece, por assim dizer, as linhas divisoras entre o que é ou não permitido na cidade num determinado momento. A lei faz da segregação o elemento estruturador do território, e não seu contrário. A conformação da 
cidade a partir do binário lepra/peste, por sua vez, permanece ainda hoje como ferramenta de hierarquização da cidade, delimitando espaços de plena cidadania e outros de isolamento ou exclusão.

Por outro lado, a cidade também é capaz de se constituir como espaço de resistência. As lutas que ali se dão anunciam reivindicações de todos os tipos, especialmente a resistência contra a privatização da cidade e da vida. Há um intenso movimento de recusa pela interdição do território (cercamento), e uma grande insatisfação no sentido de ser conduzidos, demonstrada na forma de movimentos contra a governamentalidade em vários aspectos (de Estado, de gênero, de raças etc.).

No que diz respeito às práticas urbanísticas, é necessário um reposicionamento. É preciso mudar o discurso tornando-o menos invisível; os objetivos, tendo a população como parceira; as ferramentas e as escalas mais adequadas de maneira que se possa perceber as singularidades; a prática mais do que a teoria. Enfim, é preciso sair do lugar que fomos disciplinados a estar e mudar a perspectiva a partir da qual pensamos a cidade. Na verdade é preciso mudar as perguntas e deixar abertas as interlocuções,

\section{REFERÊNCIAS}

CHOAY, F. O Urbanismo. Editora Perspectiva: São Paulo, 1992.

CLAVEL, M.M.D.C. Víctimas de un Mapa: Arquitectura y Resistencia en el Tiempo de la Cultura Flexible. Tesis doctoral presentada a la Universidad de Alicante. Departamento de Expresión Gráfica y Cartografía. Alicante, Espanha, 2012 Disponível em: <http://rua.ua.es/dspace/handle/10045/27858> Acesso em fevereiro de 2015.

FERRARI, J. Dispositivo urbanismo: entre a governamentalidade e a resistência. Tese apresentada ao Núcleo de Pós-graduação em Arquitetura e Urbanismo (NPGAU) da UFMG. Belo Horizonte, 2017

Nietzsche, a genealogia e a história. Tradução de Marcelo Catan. In: MACHADO, Roberto (org). Microfísica do Poder. Rio deJaneiro: Paz e Terra, 2015a. p. 55-86.

Sobre a história da sexualidade. Tradução de Angela Loureiro de Souza. In: MACHADO, Roberto (org.) Microfísica do Poder. Rio de Janeiro: Paz e Terra, 2015b. p. 361 a 406.

O nascimento da medicina social. Tradução de Roberto Machado. 
In: MACHADO, Roberto (org.) Microfísica do Poder. Rio de Janeiro: Paz e Terra, 2015c. p. 143-170.

. O olho do poder. Tradução de Angela Loureiro de Souza. In: MACHADO, Roberto (org.) Microfísica do Poder. Rio de Janeiro: Paz e Terra, 2015d p. 318-343.

. Vigiar e punir: nascimento da prisão. Tradução de Raquel Ramalhete. 42a ed. Petrópolis, RJ: Vozes, 2014.

. O sujeito e o poder. In: DREYFUS, Hubert; RABINOW, Paul. Michel Foucault uma trajetória filosófica: para além do estruturalismo e da hermenêutica. Tradução Vera Portocarrero e Gilda Gomes Carneiro. 2a edição rev. Rio de Janeiro: Forense Universitária, 2013a. p.273-295.

. O corpo utópico, as heterotopias. Tradução Salma Tannus Muchail. São Paulo: n-1 edições, 2013b.

O governo de si e dos outros: curso no Collège de France (19821983), tradução Eduardo Brandão. São Paulo: Editora WMF Martins Fontes (Coleção obras de Michel Foucault), 2010a.

. Em defesa da sociedade: Curso no Collège de France (1975-1976). Tradução de Maria Ermantina Galvão. 2a ed. - São Paulo: Editora WMF Martins Fontes (Coleção obras de Michel Foucault), 2010b

. A arqueologia do saber. Tradução de Luiz Felipe Baeta Neves, 7ed. - Rio de Janeiro: Forense Universitária, 2008a.

- Segurança, Território, População: Curso no Collège de France (1977-1978). Tradução Eduardo Brandão. Martins Fontes: São Paulo, 2008 b.

Nascimento da Biopolítica: Curso no Collège de France (19781979). Tradução Eduardo Brandão. São Paulo: Martins Fontes, 2008c.

. Outros espaços. In: Ditos e escritos III - Estética: Literatura e pintura, música e cinema. Rio de Janeiro: Forense Universitária, 2003.

. Historia da sexualidade I: a vontade de saber. Tradução de Maria Theresa da Costa Albuquerque e J. A. Guilhon de Albuquerque. Rio de Janeiro: Edições do Graal, 1977.

HOBBES, T. Leviatã - ou matéria, forma e poder de um Estado eclesiástico e civil. Tradução de João Paulo Monteiro e Maria Beatriz Nizza da Silva. São Paulo: Nova Cultural, 1999.

MACHADO, R. (org). Microfísica do Poder. Rio de Janeiro: Paz e Terra, 2015. 
POGREBINSCHI, T. Foucault, Para além do poder disciplinar e do biopoder. Revista Lua Nova: Revista de Cultura e Política, 2004, n 63, p. 179 a 201. Disponível em: http://www.scielo.br/pdf/ln/n63/a08n63.pdf Acesso em 15 de fevereiro de 2016.

REVEL, J. Michel Foucault: conceitos essenciais. Tradução Maria do Rosário Gregolin, Nilton Milanez, Carlos Piovesani. São Carlos: Claraluz, 2005.

TEMPLE, G. C. Poder e resistência em Michel Foucault: uma genealogia do acontecimento. Tese apresentada ao Programa de Pós-Graduação em Filosofia da Universidade Federal de São Carlos (UFSCAR). São Carlos, SP, 2011.

\title{
TERRITORY AND POPULATION: BETWEEN GOVERNMENTALITY AND RESISTANCE
}

\begin{abstract}
Governmentality, according to Foucault, is a State reason that has the population as object, the political economy as the main knowledge and the apparatus as strategic instruments of power to ensure the control of this population in order to ensure optimal economy. If we understand apparatus as a set of discursive and non-discursive elements that fulfill strategic functions for a given governmentality, it is possible to see many approaches with urbanism, understood here as a set of discursive and non-discursive knowledge that has as its objective (or strategic function) the control and ordination of bodies on the territory - where one works, lives, circulates, consumes etc. - in order to guarantee the optimal economy. On the other hand, this same city also shares territories with populations that are committed bodily in powerful actions of resistance, that is, in struggles that are beyond mere reactions to governmentality, and that express power in its operative and positive character. Based on these premises, what we intend to discuss in this essay, with reference to some urban practices in the territory, are these different mechanisms of power acting as a disciplinary force and normalizing biopolitics in search of guaranteeing governmentality, either from powerful lines of force in the sense of refusing to be governed or conducted.
\end{abstract}

Keywords: Governmentality. Power. Apparatus. Urbanism. Resistance. 


\section{TERRITORIOY POBLACIÓN: ENTRE LA GUBERNAMENTALIDADY LA RESISTENCIA}

Resumen: La gubernamentalidad, según Foucault, es una razón de Estado que tiene a la población como objeto, la economía política como principal saber y los dispositivos como instrumentos estratégicos de poder para garantizar el control de esa población en el sentido de producir la mejor economía. Si entendemos dispositivo como un conjunto de elementos discursivos y no discursivos que cumplen funciones estratégicas para una determinada gubernamentalidad, es posible ver muchas aproximaciones con el urbanismo, aquí comprendido como un conjunto de saberes discursivos y no discursivos que determina acciones de control y ordenación de la población en el territorio - donde se trabaja, reside, circula, consume, etc., con el objetivo de garantizar la mejor economía. Por otra parte, esa misma ciudad urbanísticamente determinada también alberga territorios con poblaciones comprometidas corporalmente en potentes acciones de resistencia, o sea, en luchas que están más allá de meras reacciones a la gubernamentalidad, y que expresan el poder en su carácter operatorio y positivo. A partir de estas premisas, lo que se pretende discutir en este ensayo, teniendo como referencia algunas prácticas urbanísticas en el territorio, son esos diferentes mecanismos de actuación del poder, tal sea como fuerza disciplinadora y normalizadora biopolítica en busca de garantizar la gubernamentalidad, o a partir de potentes líneas de fuerza en el sentido de la negación de ser gobernado o conducido.

Palabras Clave: Gubernamentalidad. Poder. Dispositivo. Urbanismo. Resistencia. 